Polymer Journal, Vol. 7, No. 6, pp 613-621 (1975)

\title{
The Effect of Hot and Cold Rolling on the Properties of Poly(oxymethylene)
}

\author{
Shyam BAHADUR \\ Mechanical Engineering Department and Engineering Research Institute, \\ Iowa State University, Ames, Iowa, USA.
}

(Received April 10, 1975)

\begin{abstract}
Poly(oxymethylene) was rolled uniaxially and biaxially to varying thickness reductions at ambient and 77 and $127^{\circ} \mathrm{C}$. The tensile properties of the rolled and unrolled materials were measured both in the longitudinal and transverse directions under room temperature conditions. It is found that, as a result of rolling, the tensile strength and percent elongation of the material are considerably increased in the rolling direction, with little or no appreciable effect in the transverse direction. Wide-angle $\mathrm{X}$-ray diffraction studies revealed that the preferred orientation of material during rolling takes place largely in the rolling direction and partially in the transverse direction. The rolling temperature does not seem to have any significant effect upon the preferred orientation and mechanical properties, but it affects slightly the limiting thickness reduction due to rolling. The changes in the density and mechanical properties resulting from rolling seem to be related to the morphological changes occurring in the material during the rolling process.
\end{abstract}

KEY WORDS Rolling / Tensile Strength / X-Ray Diffraction / Orientation / Poly(oxymethylene) /

The effect of cold rolling on the mechanical properties of polymers has been investigated by a number of workers. $^{1-13}$ The studies on amorphous polymers were made by Broutman and coworkers., ${ }^{4,5}$ As for the crystalline polymers, Wilchinsky ${ }^{3}$ studied the effect of cold rolling on mechanical properties for polypropylene, while Rothschild and Maxwell ${ }^{1}$ and Caddell, et al. ${ }^{8}$ investigated the same for polyethylene. The results of these studies on cold rolling may be collectively summarized as follows. Uniaxial rolling results in an increased tensile strength in the longitudinal direction, while the tensile strength in the transverse direction is not appreciably changed. As a result of biaxial rolling, the tensile strength in both the directions increases, the increase being roughly proportional to the amount of cold work due to rolling in that direction. According to Wilchinsky, ${ }^{3}$ the tensile modulus of elasticity decreases on rolling for polypropylene, while according to others ${ }^{4,6,10}$ who studied other polymers, it increases. The ductility of rolled polymers in many cases is found to be higher than that of the unrolled polymers. As investigation of this effect was made by Bahadur and Henkin. ${ }^{9}$ Studies such as these related to the effect of cold rolling on the mechanical properties are very important from the engineering standpoint.

The deformation of polymeric materials in a cold rolling process has also recently been studied by a number of workers. For example, Gezovich and Geil ${ }^{12,13}$ studied the deformation of poly(oxymethylene), poly(ethylene oxide), nylon-11, and poly(ethylene terephthalate). Hay and Keller ${ }^{14,15}$ and Frank, Keller, and $\mathrm{O}^{\prime}$ Connor ${ }^{16}$ studied the deformation of polyethylene sheets. The deformation of rolled polypropylene sheets was studied by Wilchinsky ${ }^{2}$ and Roylance, et $a .^{17}$ The wide-angle X-ray diffraction studies have shown that due to rolling the molecular chains of polyethylene, poly(ethylene oxide), and poly(ethylene terephthalate) get oriented parallel to the rolling direction..$^{12-16}$ In the case of polypropylene, ${ }^{2}$ poly(oxymethylene), ${ }^{12}$ and nylon- $11,{ }^{13}$ a preferred $c$-axis orientation inclined at a small angle $\left(20\right.$ to $\left.25^{\circ}\right)$ to the roll direction is observed for small reductions. With more severe rolling, the angle of inclination decreases to about $10^{\circ}$. 


\section{S. BAHADUR}

The investigation of the order in the crystalline texture by small-angle X-ray diffraction shows that rolling, in addition the molecular orientation, produces a rearrangement of the lamellae. For many rolled polymers, viz., polyethylene, ${ }^{15}$ poly(oxymethylene) ${ }^{12}$ nylon-11, and poly(ethylene terephthalate) ${ }^{13}$ etc., a fourpoint small-angle $\mathrm{X}$-ray diffraction pattern has been observed. Such a pattern arises due to the presence of the alternate ordered and disordered regions in the material. ${ }^{18}$ An alternative viewpoint assumes that the pattern arises from two distinct lamellar orientations, each giving rise to two of the four lobes of the pattern. ${ }^{15}$

All of the above studies relate to the rolling of polymeric materials under the ambient conditions. The purpose of the present work was to investigate the feasibility of rolling at higher temperatures and examine the effect of high temperature rolling on mechanical properties for poly(oxymethylene), a material that exhibits very low ductility at room temperature in the unrolled condition. The effect of high temperature rolling on the molecular orientation of the material was also investigated so as to relate the changes in mechanical properties in terms of the structural changes. The results presented herein were pursued more from the engineering than the structural point of view. As such, only a limited amount of evidence related to structure is included.

\section{EXPERIMENTAL}

The investigation was made on commercial poly(oxymethylene) (delrin*) that was bought from Cadillac Plastics and Chemical Co. in the form of a large sheet of about $3.45-\mathrm{mm}$ nominal thickness. The material was rolled in a 3-roll mill at the temperatures of 23,77 , and $120^{\circ} \mathrm{C}$. For rolling at temperatures above the ambient, the samples of as-received material were heated by storing them for an hour in the furnaces maintained at the intended rolling temperatures; the rolls were also raised to these temperatures by wrapping them with electrical heating tapes. The thickness reduction obtained in the first rolling step was 25-30\%. The remaining

* Trademark of du Pont Co. for poly(oxymethylene). reduction, if any, was obtained in the next step in the same succession, with no intermediate heating or cooling operation. The heavy reduction involved in each rolling step was intended to provide deformation of the sheet material throughout its entire thickness. The rolling was done both uniaxially and biaxially. The direction of uniaxial rolling was always parallel to the length of the sheet.

The tensile specimens of a nominal gage length of $32 \mathrm{~mm}$ were machined out of the unrolled and rolled samples from both the longitudinal and transverse directions. The specimens were left at room temperature for more than two weeks to permit dimensional recovery and restoration to a fully relaxed condition. The tension tests were performed at room temperature and at a crosshead speed of $5 \mathrm{~mm} / \mathrm{min}$ in an Instron machine which provided a continuous record of the load vs. extension. For each condition a minimum of two samples were tested, so as to obtain the representative behavior of materials in that condition.

The changes in crystal orientation resulting from the deformation of material in rolling were studied by wide-angle X-ray diffraction. The diffraction patterns were obtained on a Rigaku $\mathrm{X}$-ray unit using the flat plate camera and the Ni-filtered $\operatorname{CuK} \alpha$ radiation. For each sample, three diffraction patterns were obtained, with the X-ray beam incident upon the specimen from three different orthogonal directions.

The density measurements on the as-received and rolled samples were made using the ASTM D-792-64T method.

\section{RESULTS AND DISCUSSION}

\section{Limiting Reduction and Temperature Rise in Rolling}

The effect of temperature on the deformation limit of a material in a rolling process was investigated. The specimen at any particular temperature was subjected to about $30 \%$ thickness reduction in the first rolling pass. The rolled sample so obtained showed no signs of cracking (or failure) and was therefore subjected to another $30 \%$ reduction immediately, so as to minimize the heat loss from the sample to the atmosphere. For further reductions, the steps 
of both 10 and 5\% were tried without losing time in between. In the case of rolling under ambient condition, the maximum thickness reduction obtained was $60 \%$. In the case of samples heated initially to 77 and $120^{\circ} \mathrm{C}$, the limiting reduction obtained was about $70 \%$. The limiting reduction in thickness was quite repeatable. It was therefore concluded that, with the increase in rolling temperature, some improvement in the limiting reduction can be obtained.

The measurement of temperature by a surface pyrometer showed that the temperature rise in rolling was the highest in the case of samples rolled under ambient condition. For example, a $30 \%$ reduction in thickness under ambient condition resulted in a temperature rise of $17^{\circ} \mathrm{C}$ as opposed to $9^{\circ} \mathrm{C}$ in the case of rolling at 77 and $120^{\circ} \mathrm{C}$. This is understandable because the dissipation of mechanical energy needed to deform the material under ambient condition in a rolling process is much larger than that at higher temperatures. In the case of rolling at 77 and $120^{\circ} \mathrm{C}$, there was a noticeable drop in temperature between the successive rolling steps. The higher the temperature of rolling, the larger was the drop. This is probably the reason why no difference in the reduction limit was obtained in the case of rolling started at 77 and $120^{\circ} \mathrm{C}$.

\section{Effect of Rolling on Tensile Properties}

The tensile specimens (32-mm gage length) corresponding to the longitudinal and transverse directions of the unrolled and rolled poly(oxymethylene) sheet material were tested at a crosshead speed of $5 \mathrm{~mm} / \mathrm{min}$. The load $v s$. extension

Table I. Longitudinal and transverse properties of poly(oxymethylene), unrolled and rolled uniaxially and biaxially at different temperatures

\begin{tabular}{|c|c|c|c|c|c|c|}
\hline Condition & $\begin{array}{l}\text { Desig- } \\
\text { nation }^{\mathrm{a}}\end{array}$ & $\begin{array}{l}\text { Direc- } \\
\text { tion, }{ }^{b} \\
\text { L or } T\end{array}$ & $\begin{array}{c}\text { Elastic } \\
\text { modulus, } \\
\text { Mpa }\end{array}$ & $\begin{array}{c}\text { Yield }^{c} \\
\text { strength, } \\
\text { Mpa }\end{array}$ & $\begin{array}{c}\text { Ultimate } \\
\text { strength, } \\
\text { Mpa }\end{array}$ & $\begin{array}{c}\text { Elon- } \\
\text { gation, } \\
\%\end{array}$ \\
\hline As-received & a & $\mathrm{L}$ & $1.3 \times 10^{3}$ & 31.6 & 72.8 & 18.3 \\
\hline " & $\mathrm{b}$ & $\mathbf{T}$ & $1.4 \times 10^{3}$ & 32.6 & 74.1 & 13.3 \\
\hline Rolled $25 \%$ at ambient & c & $\mathbf{L}$ & $1.3 \times 10^{3}$ & 29.8 & 86.6 & 51.5 \\
\hline " & d & $\mathrm{T}$ & $1.3 \times 10^{3}$ & 36.7 & 65.6 & 18.1 \\
\hline Rolled $52 \%$ at ambient & e & $\mathrm{L}$ & $1.5 \times 10^{3}$ & 42.4 & 132.1 & 87.6 \\
\hline " & f & $\mathrm{T}$ & $1.6 \times 10^{3}$ & 42.0 & 69.0 & 11.3 \\
\hline $\begin{array}{l}\text { Rolled } 50 \% \text { biaxially at ambient } \\
(\simeq 25 \% \text { in each direction })\end{array}$ & g & $\mathrm{L}$ & $1.6 \times 10^{3}$ & 38.1 & 80.0 & 77.8 \\
\hline " & $\mathrm{h}$ & $\mathrm{T}$ & $1.5 \times 10^{3}$ & 37.5 & 89.2 & 33.6 \\
\hline Rolled $30 \%$ at $77^{\circ} \mathrm{C}$ & $\mathrm{i}$ & $\mathrm{L}$ & $1.3 \times 10^{3}$ & 28.6 & 96.4 & 33.6 \\
\hline " & $\mathrm{j}$ & $\mathrm{T}$ & $1.4 \times 10^{3}$ & 37.0 & 65.2 & 29.7 \\
\hline Rolled $50 \%$ at $77^{\circ} \mathrm{C}$ & $\mathrm{k}$ & $\mathrm{L}$ & $1.1 \times 10^{3}$ & 46.0 & 132.3 & 71.8 \\
\hline " & 1 & $\mathrm{~T}$ & $1.5 \times 10^{3}$ & 46.7 & 66.9 & 14.8 \\
\hline $\begin{array}{l}\text { Rolled } 50 \% \text { biaxially at } 77^{\circ} \mathrm{C} \\
(\simeq 25 \% \text { in each direction })\end{array}$ & $\mathrm{m}$ & $\mathbf{L}$ & $1.3 \times 10^{3}$ & 36.9 & 99.3 & 81.6 \\
\hline " & $\mathrm{n}$ & $\mathrm{T}$ & $1.4 \times 10^{3}$ & 44.2 & 71.8 & 59.4 \\
\hline Rolled $25 \%$ at $127^{\circ} \mathrm{C}$ & o & $\mathrm{L}$ & $1.1 \times 10^{3}$ & 28.7 & 96.6 & 56.7 \\
\hline " & $\mathrm{p}$ & $\mathrm{T}$ & $1.4 \times 10^{3}$ & 30.1 & 66.0 & 21.4 \\
\hline Rolled $50 \%$ at $127^{\circ} \mathrm{C}$ & $\mathrm{q}$ & $\mathrm{L}$ & $1.2 \times 10^{3}$ & 42.8 & 136.4 & 71.8 \\
\hline " & $\mathrm{r}$ & $\mathbf{T}$ & $1.4 \times 10^{3}$ & 48.4 & 65.9 & 24.4 \\
\hline $\begin{array}{l}\text { Rolled } 50 \% \text { biaxially at } 127^{\circ} \mathrm{C} \\
(\simeq 25 \% \text { in each direction })\end{array}$ & s & $\mathrm{L}$ & $1.3 \times 10^{3}$ & 37.3 & 95.1 & 66.7 \\
\hline " & $t$ & $\mathbf{T}$ & $1.3 \times 10^{3}$ & 32.8 & 77.6 & 59.3 \\
\hline
\end{tabular}

a Symbolic designation for the material condition described.

b L-longitudinal; T-transverse. For as-received and biaxially rolled materials, L implies the direction parallel to the length of the commercially bought sheet and $T$ the direction perpendicular to it.

c $0.5 \%$ offset.

d Percent thickness reduction (width change in rolling was very small). 


\section{S. BAHADUR}

plots were recorded and the values of the mechanical properties, viz., ultimate strength, yield strength, tensile elastic modulus, and percent elongation (Table I) were calculated. Since the deformation of material was always uniform in the gage length (i.e., no perceptible necking or cold drawing was observed), the true stress and true strain values werd calculated from the load-elongation data, assuming the constancy of volume in the severe tensile deformation process. The improvement in the true stress and true strain behavior as a result of cold rolling is shown in Figure 1. The effect of uniaxial and biaxial rolling at $77^{\circ} \mathrm{C}$ on the true stress-true

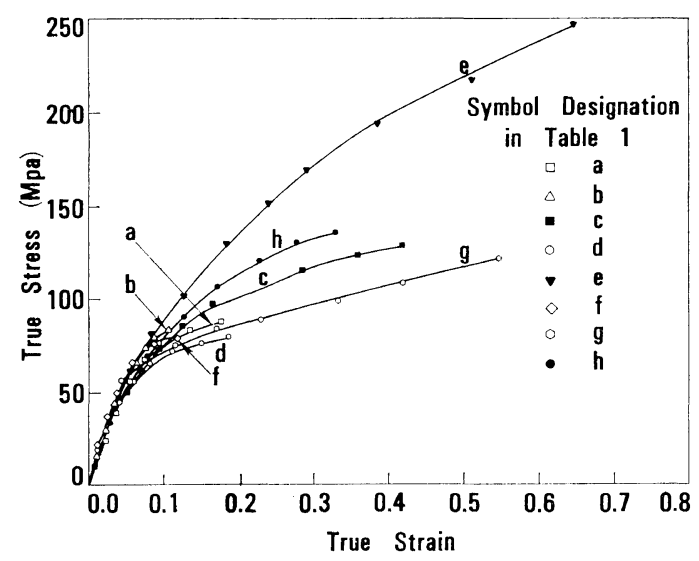

Figure 1. True stress-true strain behavior in tension of poly(oxymethylene), rolled at room temperature, in longitudinal and transverse directions.

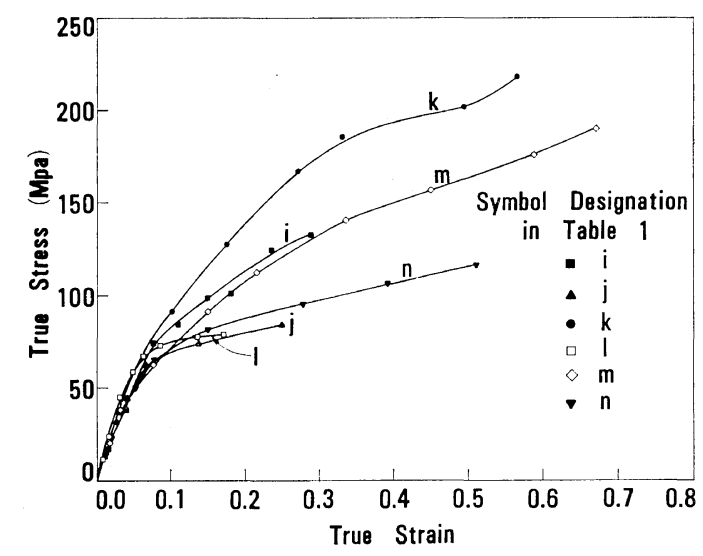

Figure 2. True stress-true strain behavior in tension of poly(oxymethylene), rolled at $77^{\circ} \mathrm{C}$, in longitudinal and transverse directions. strain behavior is shown in Figure 2 and that of rolling at $127^{\circ} \mathrm{C}$ in Figure 3. The effect of rolling temperature on the true stress-true strain behavior in the longitudinal direction is shown in Figure 4 for different percent reductions.

For each condition a minimum of two specimens were tested in tension. The values of mechanical properties reported in Table I were obtained by averaging out the test results from similar specimens. Except for the percent elongation where the variation was large, the values of other properties for both the specimens in the same condition were close. The true

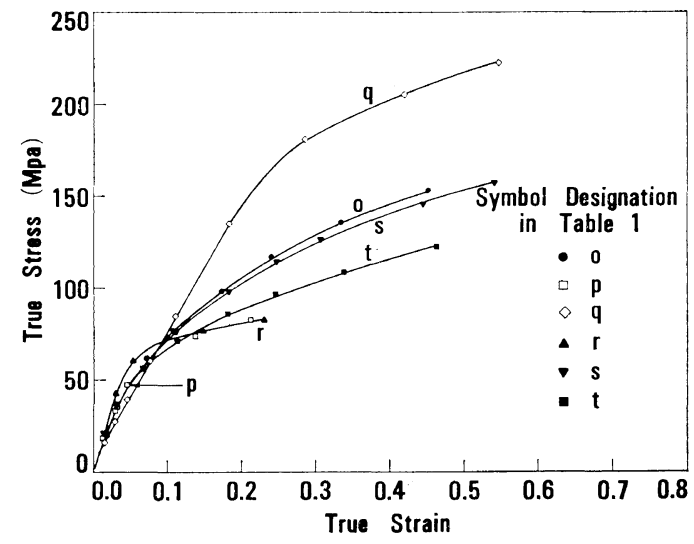

Figure 3. True stress-true strain behavior in tension of poly(oxymethylene), rolled at $127^{\circ} \mathrm{C}$, in longitudinal and transverse directions.

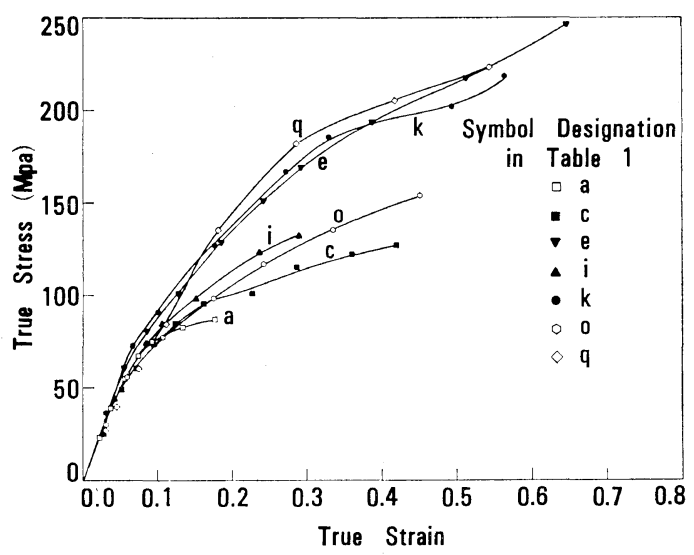

Figure 4. Effect of rolling temperature on the true stress-true strain behavior of rolled poly(oxymethylene). 
stress-true strain behavior was calculated from the test result showing larger fracture strain. This decision was made on the consideration that a specimen with inherent flaws can fail prematurely.

The following observations can be made for uniaxial rolling with respect to the mechanical properties by reference to Table I. The ultimate strength of the material increases considerably in the longitudinal direction but decreases somewhat in the transverse direction. The more the reduction in thickness due to rolling, the larger is the increase in the longitudinal tensile strength, but the decreased transverse tensile strength remains unaffected. The ultimate strength in the longitudinal direction does not seem to increase appreciably with the increasing temperature of rolling. The tensile modulus of elasticity for uniaxially rolled material is always higher in the transverse direction than in the longitudinal direction. The elastic modulus in the rolling direction remains at best unaffected (some downward trend noticeable) with the percent reduction in thickness and temperature of rolling except in the case of room temperature rolling to a $52 \%$ thickness reduction where it increases by about $17 \%$. The yield strength of the material in both the longitudinal and transverse directions is considerably increased at any temperature for the severe rolling reduction of about $50 \%$. The higher the thickness reduction, the larger is the percent elongation of the rolled material in the longitudinal direction; the ductility in the transverse direction either remains constant or increases somewhat. The rolling temperature does not seem to have any significant effect on the ductility.

In the case of biaxial rolling, the ultimate strength and percent elongation are improved in both the longitudinal and transverse directions. The yield strength is also increased, but the elastic modulus remains almost constant, except for the case of rolling under ambient condition.

Similar observations can be made from the true stress-true strain plots as well. For example, reference to Figure 1 shows that cold rolling significantly contributes to the strength and ductility of a material in the direction of rolling. The same is true for rolling at higher temperatures, as seen from Figures 2 and 3. The higher the percent reduction in thickness due to rolling, the larger is the improvement in properties. Furthermore, biaxial rolling enhances the strength and ductility in both the directions of rolling. The temperature of rolling does not seem to have any significant effect on the properties, especially at higher thickness reductions, as seen from Figure 4.

\section{Orientation Studies by Wide-Angle X-Ray Diffrac- tion}

Poly(oxymethylene) has a $9_{5}$ helix conformation and packs in a hexagonal unit cell. The wideangle X-ray diffraction patterns of the material in the unrolled and rolled conditions were obtained with the X-ray beam parallel to all the three directions $R, N$, and $T$ (Figure 5). In Figure 6a are shown the X-ray diffraction patterns for the unrolled material; these are typical of a randomly oriented crystalline material. The indexing of the diffraction pattern of an oriented sample of this material led to the conclusion that the two rings from inside to outside corresponded to $(10 \overline{1} 0)$ and (1015) reflections, respectively. The (1015) ring is hardly visible in Figure 6.

The X-ray diffraction patterns obtained from poly(oxymethylene) cold rolled to $52 \%$ thickness reduction are given in Figure $6 \mathrm{~b}$. The discrete reflections giving rise to the diffraction rings of nonuniform intensity show that the material has been oriented during the rolling process. The characteristic shape of the reflections indicates that the crystallites are imperfectly aligned. The intense equatorial (1010) reflections with the $\mathrm{X}$-ray beam normal to the rolling plane (Figure $6 \mathrm{~b} \mathrm{~N}$ ) show that the crystals are aligned with the $c$-axis of the molecules parallel to the rolling

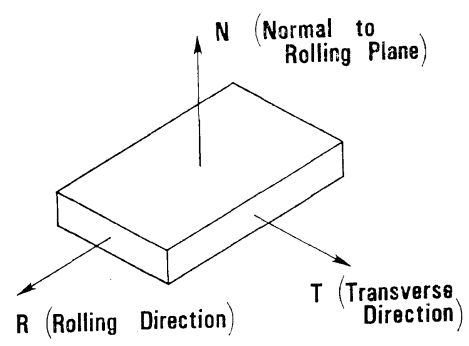

Figure 5. Orthogonal X-ray beam directions for obtaining diffraction patterns. 


\section{S. BAHADUR}

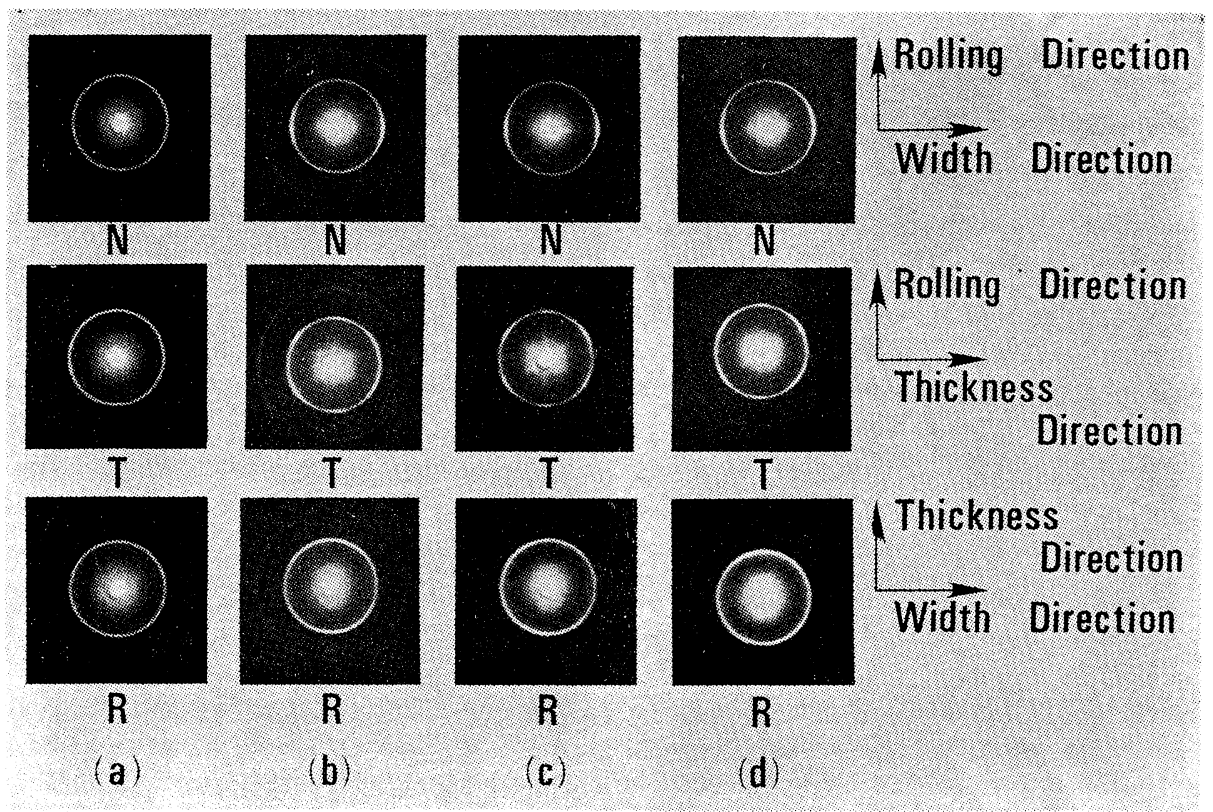

Figure 6. Wide-angle X-ray diffraction patterns: (a) unrolled poly(oxymethylene) (POM); (b) POM rolled 52\% at ambient; (c) $\mathrm{POM}$ rolled $50 \%$ at $77^{\circ} \mathrm{C}$; (d) $\mathrm{POM}$ rolled $50 \%$ at $127^{\circ} \mathrm{C}$.

direction. The meridional (1010) reflections in the X-ray diffraction pattern obtained with the $\mathrm{X}$-ray beam parallel to the rolling direction (Figure $6 \mathrm{~b} \mathrm{R}$ ) indicate the $c$-axis orientation of the rolled material in the width direction as well. Since the meridional reflections are much more diffuse than the equatorial reflections, the orientation in the width direction is considerably less than that in the rolling direction. Some transverse orientation is also indicated by the meridional reflections appearing on the diffraction pattern obtained with the X-ray beam parallel to the transverse direction (Figure 6b T). In addition, this pattern shows symmetrical reflections at about $57^{\circ}$ from the roll direction. The calculation, ${ }^{19}$ making use of the location of the two ends of the diffraction arcs, led to the conclusion that the $c$-axes of the crystallites are distributed within an angle of $15^{\circ}$ to the rolling direction. It may be noted that (1015) reflections are too weak to supply any information on the orientation pattern.

The diffraction patterns obtained from poly(oxymethylene) rolled to 50\% thickness reduction at 77 and $127^{\circ} \mathrm{C}$ are shown in Figures $6 \mathrm{c}$ and $6 \mathrm{~d}$ respectively. These patterns are analogous to those described above for the cold rolled material (Figure 6b). It may thus be inferred that the rolling at the higher temperatures employed did not alter the orientation pattern to any measurable extent.

\section{Density}

The density measurements on the material in the unrolled and rolled conditions were performed using the ASTM D-792-64T method. The density values given in Table II are based on at least two measurements carried out for each condition. These measurements were performed to get an idea of the gross molecular and lamellar readjustments occurring in the material as a result of rolling. The percent crystallinity

Table II. Density and percent crystallinity of poly(oxymethylene), unrolled and rolled at different temperatures

\begin{tabular}{lcc}
\hline \multicolumn{1}{c}{ Condition } & $\begin{array}{c}\text { Density, } \\
\mathrm{gm} / \mathrm{cm}^{3}\end{array}$ & $\begin{array}{c}\text { Crystallinity, } \\
\%\end{array}$ \\
\hline As-received & 1.424 & 68 \\
Rolled $52 \%$ at ambient & 1.409 & 62 \\
Rolled $50 \%$ at $77^{\circ} \mathrm{C}$ & 1.418 & 65 \\
Rolled $50 \%$ at $127^{\circ} \mathrm{C}$ & 1.443 & 75 \\
\hline
\end{tabular}


of the material was calculated from the measured density values. The calculated values are also given in Table II. It is noted that cold rolling reduces the density/crystallinity of the material, as already reported by a number of workers., With the increase in rolling temperature, the density as well as the crystallinity increases. This increase is probably due to the heating of the material prior to the rolling process.

\section{Structure and Property Relationship}

Poly(oxymethylene) in the as-received condition had $68 \%$ crystallinity (Table II). Thus about two-thirds of the material was comprised of the lamellar aggregates existing in the form of twisted ribbon-like structure in the spherulites, and the remainder was in the amorphous condition. The wide-angle X-ray diffraction patterns obtained from this material (Figure 6a) did not show any preferred orientation, which implies that the lamellar ribbons are randomized over all of the solid angles of the spherulite sphere. The mechanical properties of the unrolled material should therefore be isotropic, as was found (Table I).

During its passage through the rolls, the material was subjected to a compressive stress in the thickness direction, a tensile stress in the longitudinal direction, and a shear stress due to varying flow across the thickness. In the light of the gross deformation behavior in rolling, which results in increase of the length and decrease of the thickness of the sample with some effect on the width, the spherulite would be expected to elongate in the rolling direction and shorten in the thickness direction. The change of the spherulite into an ellipsoidal shape with its major axis in the pull direction was observed by O'Leary and $\mathrm{Geil}^{20}$ in the tensile deformation of poly(oxymethylene). The actual deformation of a spherulite in a rolling process would be extremely complex, due to the cooperative response of all the lamellae, which are presumed to be connected together by tie molecules. The severe contraction in the thickness direction is likely to twist the lamellar helices closer together, so that the shear stress will be exerted in the transverse plane of the lamellar axis. Since intralamellar slip has been reported to occur at very low stresses, ${ }^{21}$ this would lead to the breakup of lamellae into clumps which would finally tilt at an angle to the rolling direction. Since the fragmentation of lamellae produces partial disorder in the material, the density/crystallinity of material would decrease because of rolling. With 52\% cold work due to rolling, the density was actually found to decrease by $8.65 \%$. The lengthening of the spherulite will cause the straightening of the lamellar helices and the orientation of material in the rolling direction, as evidenced by the diffraction patterns of the rolled material (Figures $6 b-d$ ). Since the width dimension also increases somewhat during the rolling process, a similar type of deformation, though on a much smaller scale, would be anticipated for the transverse direction as well. This would cause partial orientation of the material even in this direction, as was actually observed.

When a material is subjected to tensile loading, the initial deformation is mostly of an elastic nature. In the case of rolled material, it will involve the elastic deformation of the lamellar helices, already straightened partially during the rolling process, tie molecules, and molecular chains in the amorphous regions. The resistance to this deformation and to the elastic separation between the adjacent elements due to van der Waal's forces of attraction is measured in terms of the modulus of elasticity. Due to the increased proximity and greater surface area presented by the straightened molecular ribbons and the additional area afforded by the arrangement of clumps over which van der Waal's forces of attraction act in the transverse direction, the resistance to elastic deformation in this direction is increased. Consequently, the elastic modulus of the rolled material in the transverse direction is higher than that in the longitudinal direction.

The yielding of material in a deformation process is marked by the onset of sliding between adjacent molecules in the amorphous regions followed by the extensive break-up of lamellar ribbons into clumps and their rearrangement as the stress increases. Due to the increased van der Waal's forces in the transverse direction for the reasons described above, and the high orientation of polymer molecules in the 


\section{S. BAHADUR}

longitudinal direction produced by the rolling deformation, the yield strength of the rolled material is increased in both the longitudinal and transverse directions. This increase is specially noticeable for higher percent reductions.

In the post-yield deformation, the processes on the molecular and lamellar levels that initiated yielding continue causing considerable orientation of the material in the direction of pull. The high molecular orientation in the longitudinal direction makes it difficult for a crack to propagate perpendicular to this direction so that the tensile strength of the rolled material in the longitudinal direction is con siderably increased. The larger the percent reduction, the greater is the orientation and so the higher is the ultimate strength in the rolling direction. Because of the orientation of molecules in the rolling direction, the crack can easily initiate and propagate due to the separation of molecules with the application of stress in the transverse direction, so that the transverse tensile strength of the rolled material is somewhat decreased. In the case of biaxial rolling, since the material is oriented in both the longitudinal and transverse directions, the tensile strength is also increased in both the directions.

The density measurements suggest that the crystalline structure of the material is broken up in a rolling process. Due to the characteristic deformation in rolling, which is different from that in uniaxial tension, the entanglement of disordered molecules in the amorphous regions as well as the interleaving of lamellae from adjacent spherulites on the spherulite boundaries both probably occur. The ductility of rolled material is therefore increased. Since the above effect is more pronounced in the rolling direction, the percent elongation increases more in the longitudinal direction than in the transverse direction.

The deformation of material in rolling at above-ambient temperatures would be expected to be similar to that of cold rolling. The wideangle $\mathrm{X}$-ray diffraction patterns did not show any pronounced difference in the degree of preferred orientation with temperature. There is a minor increase in the density/crystallinity of the material rolled at 77 and $127^{\circ} \mathrm{C}$ to that rolled at ambient because of the heating of the sheet material for about an hour prior to the rolling process. Since the difference in the density and orientation is very small, the mechanical properties of the rolled material do not show any significant variation with the temperature of rolling.

\section{CONCLUSIONS}

(1) Poly(oxymethylene) can be rolled satisfactorily under ambient conditions as well as at higher temperatures. The limiting reduction in thickness due to rolling is somewhat increased with the increase in rolling temperature.

(2) Due to rolling the preferred orientation of the material takes place largely in the rolling direction and partially in the transverse direction. The degree of preferred orientation does not seem to depend significantly on the rolling temperature.

(3) Due to rolling the tensile strength and percent elongation of the material are increased in the longitudinal direction. These properties depend very little upon the temperature of rolling, but very strongly upon the percent reduction in thickness due to rolling.

(4) The mechanical properties of uniaxially rolled material are highly anisotropic. With biaxial rolling the improvement in properties is obtained in both the directions.

(5) The density of the material decreases due to rolling.

(6) The mechanical properties of the rolled material seem to be related to the morphological changes occurring in the material during the rolling process.

Acknowledgment. The support for this work was provided by the Engineering Research Institute, Iowa State University, Ames, Iowa.

\section{REFERENCES}

1. P. H. Rothschild and B. Maxwell, J. Appl. Polym. Sci., 5, 16, 311 (1961).

2. Z. W. Wilchinsky, ibid., 7, 923 (1963).

3. Z. W. Wilchinsky, SPE J., 22, 46 (1966).

4. L. J. Broutman and S. Kalpakjian, ibid., 25, 46 (1969).

5. L. J. Broutman and R.S. Patil, Polym. Eng. Sci., 11, 165 (1971). 
6. A. D. Murray and K. C. Rusch, SPE J., 27, 42 (1971).

7. S. Bahadur, Polym. Eng. Sci., 13, 266 (1973).

8. R. M. Caddell, T. Bates, Jr., and G. S. Y. Yeh, Mater. Sci. Eng., 9, 223 (1972).

9. S. Bahadur and A. Henkin, Polym. Eng. Sci., 13, 422 (1973).

10. A. Peterlin, "Plastic Deformation of Polyethylene by Rolling and Drawing," A-6, IUPAC, Reprints, Toronto, 1968.

11. L. J. Broutman and S. M. Krishnakumar, Polym. Eng. Sci., 14, 249 (1974).

12. D. M. Gezovich and P. H. Geil, J. Mater. Sci., 6, 509 (1971).

13. D. M. Gezovich and P. H. Geil, ibid., 6, 531 (1971).
14. I. L. Hay and A. Keller, ibid., 1, 41 (1966).

15. I. L. Hay and A. Keller, ibid., 2, 538 (1967).

16. F. C. Frank, A. Keller, and A. O'Connor, Phil. Mag., 3, 64 (1958).

17. D. Roylance and M. Roylance, Polym. Lett., 10, 273 (1972).

18. L. E. Alexander, "X-Ray Diffraction Methods in Polymer Science,' Interscience, New York, N.Y., 1969.

19. M. Kakudo and N. Kasai, "X-Ray Diffraction by Polymers," Elsevier, New York, N.Y., 1972.

20. K. O'Leary and P. H. Geil, J. Macromol. Sci.Phys., B2 (2), 261 (1968).

21. S. Rabinowitz and N. Brown, J. Polym. Sci., Part A-2, 5, 143, (1967). 